\title{
An exploration of the biomedical optics course construction of undergraduate biomedical engineering program in medical colleges
}

Shijun Guo, Jie Lyu, Peiming Zhang

Shijun Guo, Jie Lyu, Peiming Zhang, "An exploration of the biomedical optics course construction of undergraduate biomedical engineering program in medical colleges," Proc. SPIE 10452, 14th Conference on Education and Training in Optics and Photonics: ETOP 2017, 104524C (16 August 2017); doi: $10.1117 / 12.2266627$

Event: 14th Conference on Education and Training in Optics and Photonics, ETOP 2017, 2017, Hangzhou, China 


\title{
An Exploration of the Biomedical Optics Course Construction of Undergraduate Biomedical Engineering Program in Medical Colleges
}

\author{
Guo Shijun ${ }^{1,2,{ }^{*}}$, Lyu Jie ${ }^{1}$, Zhang Peiming ${ }^{1}$ \\ 1 School of Medical Instrumentation, Shanghai University of Medicine \& Health Sciences, Shanghai 201318, P.R.China \\ 2 School of Optical-Electrical and Computer Engineering, University of Shanghai for Science \& Technology, Shanghai 200093, \\ P.R.China \\ *Email: guosj@sumhs.edu.cn
}

In this paper, the teaching goals, teaching contents and teaching methods in biomedical optics course construction are discussed.

From the dimension of teaching goals, students should master the principle of optical inspection on the human body, diagnosis and treatment of methodology and instruments, through the study of the theory and practice of this course, and can utilize biomedical optics methods to solve practical problems in the clinical medical engineering practice.

From the dimension of teaching contents, based on the characteristics of biomedical engineering in medical colleges, the organic integration of engineering aspects, medical optical instruments, and biomedical aspects dispersed in human anatomy, human physiology, clinical medicine fundamental related to the biomedical optics is build. Noninvasive measurement of the human body composition and noninvasive optical imaging of the human body were taken as actual problems in biomedical optics fields. Typical medical applications such as eye optics and laser medicine were also integrated into the theory and practice teaching.

From the dimension of teaching methods, referencing to organ-system based medical teaching mode, optical principle and instrument principle were taught by teachers from school of medical instruments, and the histological characteristics and clinical actual need in areas such as digestive diseases and urinary surgery were taught by teachers from school of basic medicine or clinical medicine of medical colleges. Furthermore, clinical application guidance would be provided by physician and surgeons in hospitals.

Keywords: biomedical optics, course construction, integration, organ-system based

\section{Re-examination of teaching objectives}

\subsection{Biomedical engineering training model in China}

Biomedical engineering education in China started in 1980s, mainly in engineering colleges/universities and medical colleges/universities. The construction and development mode of biomedical engineering in these two types of colleges/universities has its own emphasis, follows the common discipline foundation, and is of significant features in the application level, the cultivation of biomedical engineering professionals. Relatively speaking, the biomedical engineering training mode of engineering colleges/universities pay attention to the development of 
engineering technology and function expansion, while medical colleges/universities pay attention to the combination of medicine and engineering, the comprehensive application of engineering technology in medicine [1].

At present, it is one of the remarkable features of medicine and health science that the high degree of integration of subjects, and it puts forward higher requirements for the cultivation of talents in the field of medicine and health. Medical and health professionals not only need to have a solid professional quality, but also should be good at using an open field of vision, rich theoretical literacy and practical ability to analyze and solve a variety of clinical practical problems.

\subsection{Orientation of undergraduate biomedical engineering program in SUMHS}

Medical instruments and medical imaging devices are the mainstream products in the modern medical equipment industry, and play a leading role in the industry development. Its development level has become one of the important symbols of comprehensive economic and technical strength of one country. Industrialization is also a driving force for the development of the discipline, but also lays a good foundation for the future career development of students [2]. Based on the trend of medical health needs and the development of life sciences, medical instruments and medical imaging technologies including biomedical optics, have good application and development prospects, and have become the focus of the development direction of biomedical engineering.

The training scheme for undergraduates of biomedical engineering in Shanghai University of Medicine \& Health Sciences (SUMHS) points out that, students should have a broad theoretical knowledge on biology, medicine and optical-mechanical-electrical engineering technologies, and accept training of modern medicine and the typical medical application. Students not only can engage in clinical engineers to solve clinical engineering issues, realize of medical safety management, and help promoting treatment or nursing care of patients, but also can engage in technology research, development and applications in the field of biomedical engineering technology in such as medical, scientific research and manufacturing enterprise.

\subsection{Teaching objectives of biomedical optics}

Biomedical optics is the methodology and instrumentation for the examination, diagnosis and treatment of human body by optical principles. Biomedical optical methods and devices are widely used in medical technology departments such as department of laboratory, pathology, and clinical medical departments such as department of gastroenterology, urology, ophthalmology, ear-nose-throat and et al. Therefore, biomedical optics is one key course of biomedical engineering, and its teaching objectives include: to master the basic concepts of optics, laser technology and biomedical optics, interaction between light and biological tissue and its biological effect, microscopic imaging technology and its application in biological medicine, biomedical spectroscopy, laser medical application; and to cultivate the ability of using biomedical optics manners to solve practical problems, so as to serve clinical medicine and engineering practice. 


\section{Teaching contents integration and establishment}

\subsection{Curriculum integration method}

The integrated curriculum refers to collecting and merging of the teaching contents in original related courses or teaching processes, as to form a new course of reasonable and coordinated contents. The integration purpose is to emphasize the integrity of knowledge, and to cultivate students' comprehensive ability to use knowledge to solve practical problem [3]. One of the main curriculum models of integrated medical curriculum is the curriculum model based on organ system [4].

The specialty and interdisciplinary development of medicine and health sciences are the two sides of one coin in the medicine development. Similarly, the subject subdivision and curriculum integration in the teaching are not contradictory. Under the traditional curriculum model, students' knowledge is one-sided, narrow, closed and fragmentary, which is the result of the lack of communication between different subjects. Therefore, curriculum integration is not to immediately break the subject-based faculty construction, but should eliminate the barriers between teachers of different disciplines, and provide a convenient platform for the teaching and research, academic communication and cooperation.

\subsection{The establishment of teaching contents}

According to the design concept of integrated curriculum, the curriculum construction and integrated teaching afford an opportunity to promote the organic combination of engineering and clinical medicine. The main contents of this course include the basic concept of biomedical optics, the interaction between light and tissue and its biological effects, the application of optical technology in biomedicine. The main basis of this course is the application and maintenance of medical optical devices, including the basic principle of geometric optics, physical optics, the basic knowledge and techniques such as working principle, system structure, application and maintenance of the medical optical instruments.

Through the construction of biomedical optics course, the organic integration of the original curriculum, the basis of medical optical devices, medical laser devices, and such fields related to biomedical optics dispersed in the courses of human anatomy, human physiology, introduction to clinical medicine, introduction to medical devices, and et al. Through the theoretical and practical training of the course, the students can solve the practical problems by using the method of biomedical optics in clinical medicine and engineering practice.

\section{Teaching methods selection and implementation}

\subsection{Application of PBL teaching method}

In order to achieve the teaching objectives of biomedical optics course, students need to learn the knowledge of multiple disciplines, master the ability to analyze and solve problems. The traditional lecture-based learning (LBL) method cannot meet the practical needs. The problem-based learning (PBL) emphasizes that studying in complex and meaningful problem 
situation, to solve the real problem by learning cooperation, thus learning implicit in the science behind the problem knowledge, skills and ability to solve the problems of autonomous learning. It stimulates students' interest in learning, cultivate students' ability to discover and solve problems, so as to meet the needs of the new situation of biomedical engineering teaching.

The noninvasive measurement of human body composition and noninvasive optical imaging of human body are the two practical problems of biomedical optics. The typical medical applications such as optometry and laser medicine are also integrated into the theory and practice teaching. In this course, the principle of optics and optical devices are taught by teachers of School of Medical Instrumentation, SUMHS, the histology and clinical needs in the fields such as gastroenterology and urology are taught by teachers of School of Basic Medicine or School of Clinical Medicine, SUMHS, and the clinical applications guidance would be provided by chief physicians and surgeons of Affiliated Hospitals of SUMHS.

\subsection{Cultivation of practical and innovation ability}

Based on the experiments in class, it would be appropriate to allow students to participate in teachers' real research projects or just one project work, which let students make full use of their practical and innovation ability, at the same time to complete the project.

Different from other engineering colleges/universities, medical colleges/universities can make full use of the valuable resources of affiliated hospitals, and share resources in medical equipment and clinical engineering talents. Students could do their probation, internship and graduation thesis in relevant departments of the affiliated hospital. Hence, students could contact medical optics and laser devices as soon as possible, experience the medical devices operation, equipment management, technical support and other training, having the opportunity to fully understand the clinical requirements of engineering technology, so as to improve the students' practical ability.

\section{References}

[1] Chen Chaomin, Zhou Linghong, Gong Jian, et al.," The reform and research about the professional training mode of biomedical engineering in nowadays (in Chinese)," China Higher Medical Education 19(1), 22-26 (2005).

[2] Li Haiyun, Jing Bin, Yu Hongyu, "Investigation on discipline construction of biomedical engineering (in Chinese), Beijing Biomedical Engineering 34(6), 626-629 (2015).

[3] Zheng Jun, Ma Jianhui, Wu Xiongwen, et al.," Practice and exploration of integrated medical curriculum model (in Chinese)," China Higher Medical Education 22(9), 7-8 (2008).

[4] Smith, M. E., Morton, D. G., [The Digestive System: Systems of the Body Series (Second Edition)], Elsevier Health Sciences, 2-8 (2010). 